\title{
Clinical and Pathological Features of Ulcerative Colitis in Patients with and without Clostridium Difficile Infection; An Observational Study
}

\author{
Najmeh Aletaha ${ }^{1}$, Zohreh Dadvar ${ }^{1, *}$, Babak Salehi ${ }^{2}$, Pardis Ketabi Moghadam ${ }^{3}$, Ali Niksirat ${ }^{1}$, \\ Akram Jowkar ${ }^{1}$, Reza Taslimi ${ }^{1}$, Seyed Farshad Allameh ${ }^{1}$, Naser Ebrahimi Daryani ${ }^{1}$
}

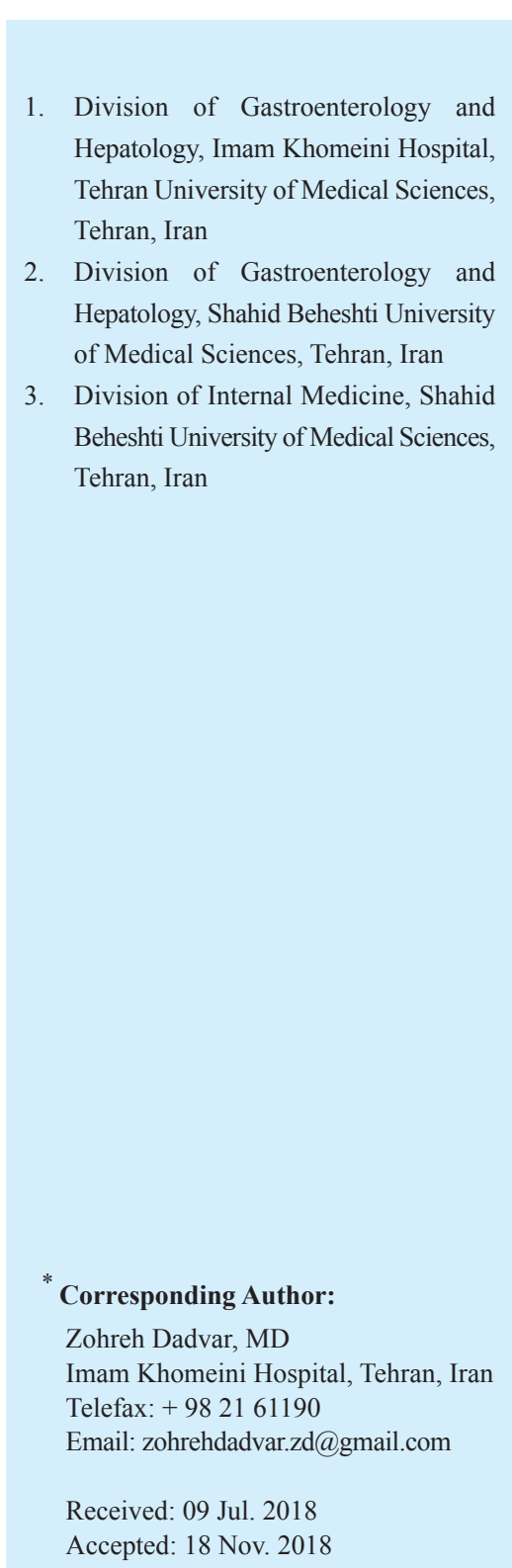

\section{ABSTRACT}

\section{BACKGROUND}

A dramatic rise in the rate of clostridium difficile infection (CDI) in patients with inflammatory bowel disease (IBD) has been reported in recent years.

\section{METHODS}

In this observational case control study, 65 patients ulcerative colitis (UC) with flare up were included and were divided into two groups of UC + CDI as case group and UC without CDI as control group.

\section{RESULTS}

35 patients who had positive test for clostridium difficile were assigned to the case group. The control group consisted of 30 patients with negative test for clostridium difficile. Pancolitis was seen in the cases more statistically significant than the controls and proctitis was seen more among the controls than the cases $(p=0.001)$. The cases were on immunosuppressive $(p=0.001)$ and antibiotic $(p=0.02)$ therapy more than the controls. Colonoscopic findings revealed more severe and extensive inflammation among the cases versus milder inflammation among the controls, but these differences were not statistically significant $(p=0.2)$. Colectomy was seen in $10 \%$ of controls and none of the cases and this difference was statistically significant ( $p$ value $=0.05$ ). More fecal calprotectin were seen among the cases than the controls and this difference was statistically significant $(p<0.05)$

\section{CONCLUSION}

This study showed more clostridium difficile infection among the patients on antibiotic or immunosuppressive therapy. Pathological investigation revealed more severe and extensive inflammation among the cases than the controls. Cases had clinically more severe signs and symptoms with higher mayo scores than the controls. ESR (Erythrocyte sedimentation rate) and fecal calprotectin were higher in patients with positive clostridium difficile infection and serum albumin was lower in such patients.

\section{KEYWORDS:}

Clostridium Difficile, Ulcerative Colitis, Infection

\section{Please cite this paper as:}

Aletaha N, Dadvar Z, Salehi B, Ketabi Moghadam P, Niksirat A, Jowkar A, Taslimi R, Allameh SF, Ebrahimi Daryani N. Clinical and Pathological Features of Ulcerative Colitis in Patients with and without Clostridium Difficile Infection; An Observational Study. Middle East J Dig Dis 2019;11:17-23. doi: 10.15171/mejdd.2018.123.

\section{INTRODUCTION}

Ulcerative colitis (UC) is a chronic mucosal disease that usually involves the rectum in almost all of the patients and can extend proximally to sigmoid, transverse and ascending colon, and even in to the end of terminal ileum. This 
extension is continuous without skip areas of normal mucosa. About one fifth of patients have total colitis.

The most important symptoms of patients with UC are diarrhea, passage of mucus, passage of bloody mucus, bloody diarrhea, and crampy pain. Rectal urgency, tenesmus, rectal bleeding, and incomplete evacuation feeling are most commonly seen in patients with proctitis. Patients during the disease period have exacerbations and remissions due to treatment or nature of the disease itself.

Histological findings is usually consistent with the endoscopic appearance and clinical signs and symptoms. This disease is limited to mucosa or superficial submucosa except for fulminant disease, which affect deeper layers of the colon. The hallmarks of UC in microscopic view are crypt distortion and basal plasma cells and lymphoid aggregates with focal hemorrhage in lamina propria. ${ }^{1}$

Clostridium difficile is a gram positive, spore forming, obligately anaerobic bacillus, which is found in the environment and can involve the colonic mucosa that has lost its normal microbiota by means of widespread antimicrobial usage, so clostridium difficile infection (CDI) can be seen during hospital admissions or immediately after discharge. Its diagnosis and treatment is difficult because of its paradoxical nature, which is resulted and treated both by antibiotics. ${ }^{2}$ The most common manifestation of CDI is diarrhea, which is not grossly bloody and can be soft or watery with sometimes as many as 20 daily bowel movements. The other manifestations are fever, leukocytosis, abdominal pain, ileus, hypoalbuminemia, and even fulminant colitis. ${ }^{3}$

The diagnosis of CDI is based on the detection of toxin $\mathrm{A} / \mathrm{B}$ on stool or detection of toxin $\mathrm{A} / \mathrm{B}$ producing clostridium difficile on stool by polymerase chain reaction (PCR) or culture and pseudomembrane visualization at endoscopy. ${ }^{4}$ Some CDIs have been reported in outpatient cases without history of antibiotic usage. .-6 $^{5}$ Spores of toxigenic clostridium difficile are ingested and colonized in lower intestinal tract. They produce toxin A (enterotoxin) and toxin B (cytotoxin) which can destroy the colonic mucosa and result in pseudomembrane formation and diarrhea. ${ }^{7-12}$

A dramatic change in the epidemiology of CDI has occurred in recent years. Some studies have shown that the rate of CDI has tripled between 2000 and 2005 in the United States. ${ }^{13}$ Long term medical therapy, periodic hospital admissions, and even surgery, and chronic use of antibiotics and corticosteroids and immunomodulators have been shown to increase the risk of CDI in patients with inflammatory bowel disease (IBD). ${ }^{13,14}$ Some studies show no increase of CDI among patients receiving biological agents. ${ }^{15}$

There is an alarming increase in the morbidity, mortality, need for surgery, and healthcare cost resulting from CDI among patients with IBD. So clostridium difficile is currently an important public health issue for gastroenterologists. The most important point is that how CDI can alter the natural history of UC and Crohn's disease (CD), which is able to make their course worsen and longer. One of the most important approaches necessary for patients with CD and UC hospitalized for flair signs and symptoms, is detection of opportunistic agents such as cytomegalovirus and clostridium difficile or progression of the underlying IBD as causative agent of flair. Previous studies have reported that about $20 \%$ of patients admitted for relapsing IBD have positive test for clostridium difficile. However, more studies are required to estimate the incidence of clostridium difficile associated diarrhea (CDAD) in hospitalized patients with $\mathrm{CD}$ and UC. ${ }^{16-20}$ There are some studies that show both clostridium difficile carriage and CDAD may be seen without previous antibiotic exposure. ${ }^{3}$

We decided to make a comparison between IBD patients with and without CDI for evaluating risk factors, pathological, and clinical signs and symptoms.

\section{MATERIALS AND METHODS}

This study was an observational case control study conducted on patients referred to our center during 20152017. We had the ethical committee approval for our study. Patients with definite colonoscopic and pathological evidence of UC who referred to our center (Imam Khomeini hospital in Tehran) with flare up signs and symptoms of UC entered the study and underwent colonoscopy and biopsy sampling for pathology report and stool analysis for clostridium difficile detection with VIDAS Clostridium Difficile Toxin A\&B kit made by French biomerieux company. 35 patients with CDI positive tests and UC flare up signs and symptoms were considered as case group and 30 patients with UC flare up and negative CDI tests were considered as control group. Patients were 
enrolled in this study after providing a written consent. Statistical analyses were performed. Age, sex, CDI test results, signs and symptoms of the disease, colonoscopy results, pathological results, and history of previous antibiotic or immunosuppressive agent usage were evaluated. Six months follow-up for complications (surgeries like ileal pouch anal anastomosis or colectomy) of the mentioned groups were studied. An experienced pathologist who was blind to CDI test results was involved. The severity of the disease was assessed by mayo score scale.

\section{RESULTS}

65 patients with UC who had flare up signs and symptoms were included in the study. 35 patients who had positive C. difficile tests went assigned to the case group, 21 of them $(60 \%)$ were women and $14(40 \%)$ were men. The mean age was $35 \pm 10$ years. There were 30 patients in the control group with negative C. difficile tests, $60 \%$ of them were women and $40 \%$ were men. The mean age was $34 \pm 9.5$ years.

Comorbidities stratified in each case and control groups. In case group; one patient (2.9\%) had anemia, one patient (2.9\%) had CMV (Cytomegalovirus) colitis, one patient $(2.9 \%)$ had diabetes mellitus and hypertension, one patient (2.9\%) had $H B V$ (Hepatitis B virus) infection, one patient $(2.9 \%)$ had PSC (Primary sclerosing cholangitis), one patient (2.9\%) had peptic ulcer disease, one patient had depression, three of them (8.6\%) had thyroid dysfunction, and the remaining 25 patients did not have any comorbidities. In the control group we had one patient (3.3\%) with anemia, one patient (3.3\%) with asthma, one patient with $(3.3 \%)$ auto immune hepatitis (AIH), one patient (3.3\%) with arthritis, one patient (3.3\%) with IBS, seven patients $(23.3 \%)$ with other comorbidities, and the remaining 18 patients did not have any comorbidities.

$28.6 \%$ of the cases and $13.3 \%$ of the controls had positive history of clostridium difficile infection. $8.6 \%$ of the cases and none of the controls had history of pathologically documented $C M V$ infection.

$2.9 \%$ of the cases and $3.3 \%$ of the controls had history of appendectomy. $2.9 \%$ of the cases and none of the controls had history of fistula. Other previous infectious diseases and surgical histories were seen in $8.6 \%$ and
$5.7 \%$ of the controls and none of the cases.

$11.2 \%$ of the cases and $10 \%$ of the controls had positive family history for IBD. $22.9 \%$ of the cases and $30 \%$ of the controls were smokers. $8.6 \%$ of the cases and none of the controls were alcoholics.

$53.3 \%$ of the controls and $40 \%$ of the cases had abdominal pain, $50 \%$ of the controls and $51.4 \%$ of the cases had diarrhea. $80 \%$ of the patients in both case and control groups had bleeding. $26.7 \%$ of the controls and $31.4 \%$ of the cases had weight loss as the first sign of flare up syndrome resulting to hospital admission.

Left colitis was seen in $2.9 \%$ of the cases and $53.3 \%$ of the controls. Pancolitis was seen in $65.7 \%$ of the cases and none of the controls. Proctitis was seen in none of the cases and $13.3 \%$ of the controls. $100 \%$ of the cases were on immunosuppressive therapy versus $70 \%$ of the controls. $34.3 \%$ of the controls and only $10 \%$ of the cases were receiving antibiotics $(p<0.05)$.

$2.9 \%$ of the controls and $10 \%$ of the cases were ANA (Antinuclear antibody) positive. 5.7\% of the cases and $6.7 \%$ of the controls were ANCA (Anti-neutrophil cytoplasmic antibody) positive.

Colonoscopic findings revealed $5.7 \%$ of the cases and $20 \%$ of the controls had mild mucosal inflammation. Moderate inflammation was seen in $31.4 \%$ of the cases and $30 \%$ of the controls. Severe inflammation was seen in $60 \%$ of the cases and in $50 \%$ of the controls. Yellowish mucosa was seen in $2.9 \%$ of the cases and in none of the controls.

In pathological reports $5.7 \%$ of the cases and none of the controls had $C M V$ colitis. $2.9 \%$ of the cases and none of the controls had $C M V$ destructive colitis.

None of the cases and $10 \%$ of the controls underwent colectomy. None of the cases or controls underwent IPAA (ileal pouch-anal anastomosis). Mortality was not seen among the cases and controls during this 6-month follow-up. $94.3 \%$ of the cases and $56.7 \%$ of the controls had positive fecal calprotectin $(p=0.001) .60 \%$ of the cases and $46.7 \%$ of the controls had positive serum CRP levels $(p=0.2)$. ESR was higher in patients with clostridium difficile infection and serum albumin was lower in these patients.

Mean Mayo scores among the cases was $8.9( \pm 2.3)$ versus $6.3( \pm 3)$ among the controls $(p=0.0001)$. Laboratory tests averages are depicted in tables 1 and 2. Demographic data are showed in table 3 . 
Table 1: Comparing CBC parameters between the case and control groups

\begin{tabular}{lcccc}
\hline CBC Parameters & WBC (per microliter) & Hb (mg/dl) & MCV (fL) & Plt (per microliter) \\
\hline UC & $6846.7 \pm 1952.6$ & $12.6 \pm 2.4$ & $81.7 \pm 9.1$ & $313000 \pm 87.3$ \\
\hline UC-cdiff & $7267.4 \pm 2243$ & $15.8 \pm 4.9$ & $78.5 \pm 7.2$ & $354.6 \pm 136.3$ \\
\hline$P$ value & 0.427 & 0.242 & 0.115 & 0.159 \\
\hline WBC: white blood cell, Hb: hemoglobin, $M C V:$ mean corpuscular value, Plt: platlet, UC: ulcerative colitis, cdiff: clostridium difficile (all values need units. $P$ values should be in culomns.)
\end{tabular}

Table 2: Comparing ESR, BUN, $\mathrm{Cr}$, and albumin between case and control groups

\begin{tabular}{|c|c|c|c|c|}
\hline & $\operatorname{ESR}(\mathrm{mm} / \mathrm{h})$ & BUN (mg/dL) & $\mathrm{Cr}(\mathrm{mg} / \mathrm{dL})$ & $\operatorname{Alb}(g / d L)$ \\
\hline $\mathrm{UC}$ & $17.9 \pm 11$ & $20.3 \pm 8.5$ & $0.83 \pm 0.19$ & $3.8 \pm 0.35$ \\
\hline UC-cdiff & $33.49 \pm 25$ & $20.7 \pm 10.5$ & $0.86 \pm 0.17$ & $3.09 \pm 0.45$ \\
\hline$P$-value & 0.002 & 0.87 & 0.47 & 0.001 \\
\hline
\end{tabular}

Table 3: Demographic data of the patients

\begin{tabular}{lcccc}
\hline & Number of patients & Male & Female & Mean age (years) \\
\hline UC & 30 & $40 \%$ & $60 \%$ & $34 \pm 9.5$ \\
\hline UC-cdiff & 35 & $40 \%$ & $60 \%$ & $35 \pm 10$ \\
\hline
\end{tabular}

\section{DISCUSSION}

In this study $34.3 \%$ of the cases and only $10 \%$ of the controls had received antibiotics during the month preceding the episode of flair $(p<0.05)$. This epidemiological difference suggests that intestinal flora change in patients with IBD could result in the spread of clostridium diffcile. ${ }^{20-24}$ Patients with IBD may show a certain degree of epithelial dysfunction by immune stimulation and increased mucosal permeability, which can result in clostridium difficile colonization and proliferation. ${ }^{25-27}$

All of cases were on immunosuppressive therapy versus $70 \%$ of the controls $(p=0.001)$. These results were not consistent with other studies that showed no increased risk of infection among patients receiving anti-TNF drugs. Different previous studies have shown mixed results in relation between corticosteroid therapy and the risk of CDI. Various studies have demonstrated an increased risk with systemic administration of immunomodulators. ${ }^{28-30}$

No mortality was detected in patients with IBD + CDI, which was an expected result considering the relatively young patients and low comorbidity. ${ }^{31}$ Previous history of smoking or alcohol consumption was asked from the population under study which was not statistically different between the cases and controls. None of the cases required colectomy or IPAA that is somehow different from other studies. ${ }^{22}$ Because of the small number of patients in this study, more studies should be done to rule out no more mortality and complication in patients with IBD following CDI.

Some authors have shown a higher incidence of CDI in patients with active IBD and it has been suggested that CDI might be responsible in the initial pathogenesis of some epidemics of IBD. ${ }^{32}$ Unfortunately, colonoscopy is not a perfect tool to confirm CDI because pseudomembranes appear less frequently in patients with IBD (approximately $9 \%$ ), especially in the absence of fever. This property may be related to differences in the infection associated with chronic IBD inflammation. ${ }^{33-37}$ In fact, $2.9 \%$ of our patients exhibited endoscopic signs of activity together with microbiological detection of CDI.

Pathological investigation revealed more severe and extensive inflammation among cases than controls, which was statistically significant. Proctitis was seen exclusively among the controls. The cases referred to our center had clinically more severe signs and symptoms with higher mayo scores than controls. The incidence of different first signs and symptoms of cases and controls is depicted in figure 1 .

The cases had high calprotectin in their stool exam 


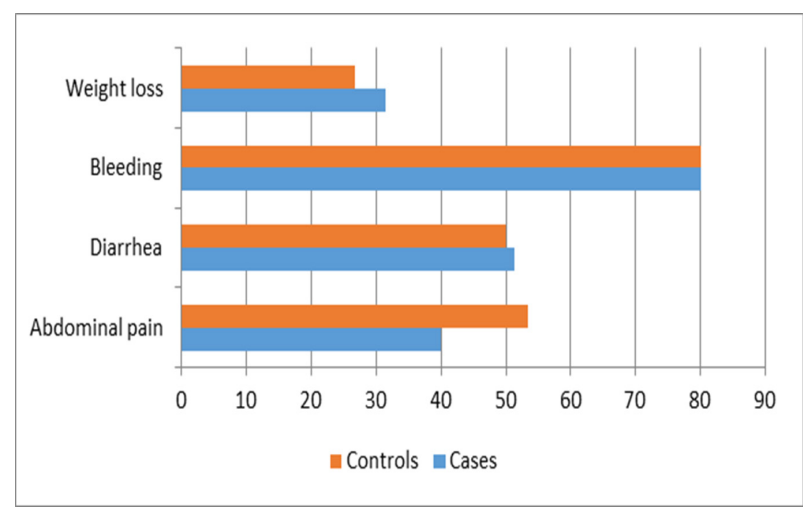

Fig.1: First signs and symptoms of flair in cases and controls

and elevated ESR and low albumin in comparison with the control group, which was statistically significant, emphasizing the using simple stool exam and ESR or albumin as the first laboratory test in patients with flare. These results are somehow different from other studies that show that coinfection of clostridium difficile and IBD are not predictable by ESR or stools exam. ${ }^{23}$ In contrast, serum CRP levels were not significantly different between the cases and controls.

The limitation of our study was low sample size. This study did not include the available challenges for treatment of IBD patients with CDI. But in summary most of the cases were resistant to classic treatments and needed more modern techniques of CDI treatment such as fecal transplantation. Overall, we recommend clinicians to consider CDI with every flare of symptoms in patients with IBD. Initial diagnosis, proper treatment, and prevention of CDI in patients with IBD can improve outcomes and preserve the quality of life in such patients.

\section{ETHICAL APPROVAL}

There is nothing to be declared.

\section{CONFLICT OF INTEREST}

The authors declare no conflict of interest related to this work.

\section{REFERENCES}

1. Kornbluth A, Sachar DB. Ulcerative Colitis Practice Guidelines in Adults: American College Of Gastroenterology, Practice Parameters Committee. Am J Gastroenterol 2010;105:501-23. doi:10.1038/ajg.2009.727.
2. McDonald LC, Owings M, Jernigan DB. Clostridium difficile infection in patients discharged from US short-stay hospitals, 1996 to 2003. Emerg Infect Dis 2006;12:40915. doi:10.3201/eid1205.051064.

3. Issa M, Ananthakrishnan AN, Binion DG. clostridium difficile and inflammatory bowel disease. Inflamm Bowel Dis 2008;14:1432-42. doi:10.1002/ibd.20500.

4. Lamps L. Infectious disorders of the GI tract. In: Odze R, Goldblum J, eds. Surgical Pathology of the GI Tract, Liver, Biliary Tract and Pancreas. 2nd ed. Philadelphia, PA: Saunders Elsevier; 2009:51-79.

5. Kelly CP, LaMont JT. Clostridium difficile more difficult than ever. N Engl J Med 2008;359:1932-40. doi:10.1056/ NEJMra0707500.

6. Singh S, Graff LA, Bernstein CN. Do NSAIDs, antibiotics, infections, or stress trigger flares in IBD? Am J Gastroenterol 2009;104:1298-313. doi:10.1038/ajg.2009.15.

7. Samore MH, Bettin KM, DeGirolami PC, Clabots CR, Gerding DN, Karchmer AW. Wide diversity of Clostridium difficile types at a tertiary referral hospital. J Infect Dis 1994;170:615-21. doi:10.1093/infdis/170.3.615.

8. Poxton IR, McCoubrey J, Blair G. The pathogenicity of Clostridium difficile. Clin Microbiol Infect 2001;7:421-7. doi:10.1046/j.1198-743x.2001.00287.x.

9. Johnson S, Clabots CR, Linn FV, Olson MM, Peterson LR, Gerding DN. Nosocomial Clostridium difficile colonisation and disease. Lancet 1990;336:97-100. doi: 10.1016/0140-6736(90)91605-A.

10. Haslam SC, Ketley JM, Mitchell TJ, Stephen J, Burdon DW, Candy DC. Growth of Clostridium difficile and production of toxins A and B in complex and defined media. J Med Microbiol 1986;21:293-7. doi:10.1099/0022261521-4-293.

11. Karlsson S, Dupuy B, Mukherjee K, Norin E, Burman LG, Akerlund T. Expression of Clostridium difficile toxins A and B and thair sigma factor TcdD is controlled by temperature. Infect Immun 2003;71:1784-93.

12. Dupuy B, Sonenshein AL. Regulated transcription of Clostridium difficile toxin genes. Mol Microbiol 1998;27:107-20. doi:10.1046/j.1365-2958.1998.00663.x.

13. Rodemann JF, Dubberke ER, Reske KA, Seo DH, Stone $\mathrm{CD}$. Incidence of Clostridium difficile infection in inflammatory bowel disease. Clin Gastroenterol Hepatol 
2007;5:339-44. doi:10.1016/j.cgh.2006.12.027.

14. Issa M, Vijayapal A, Graham MB, Beaulieu DB, Otterson MF, Lundeen S, et al. Impact of Clostridium difficile on inflammatory bowel disease. Clin Gastroenterol Hepatol 2007;5:345-51. doi:10.1016/j.cgh.2006.12.028.

15. Schneeweiss S, Korzenik J, Solomon DH, Canning C, Lee J, Bressler B. Infliximab and other immunomodulating drugs in patients with inflammatory bowel disease and the risk of serious bacterial infections. Aliment Pharmacol Ther 2009;30:253-64. doi:10.1111/j.13652036.2009.04037.x.

16. Meyer AM, Ramzan NN, Loftus EV, Heigh RI, Leighton JA. The diagnostic yield of stool pathogen studies during relapses of inflammatory bowel disease. $J$ Clin Gastroenterol 2004;38:772-5. doi:10.1097/01. mcg.0000139057.05297.d6.

17. Mylonaki M, Langmead L, Pantes A, Johnson F, Rampton DS. Enteric infection in relapse of inflammatory bowel disease: importance of microbiological examination of stool. Euro J Gastroenterol Hepatol 2004;16:775-8. doi: 10.1097/01.meg.0000131040.38607.09.

18. Nguyen GC, Kaplan GG, Harris ML, Brant SR. A national survey of the prevalence and impact of Clostridium difficile infection among hospitalized inflammatory bowel disease patients. Am J Gastroenterol 2008;103:1443-50.

19. Kariv R, Navaneethan U, Venkatesh PG, Lopez R, Shen B. Impact of Clostridium difficile infection in patients with ulcerative colitis. J Crohns Colitis 2011;5:34-40. doi:10.1016/j.crohns.2010.09.007.

20. Saidel-Odes L, Borer A, Odes S. Clostridium difficile infection in patients with inflammatory bowel disease. Ann Gastroenterol 2011;24:263-270.

21. Ramos-Martínez A, Ortiz-Balbuena J, Curto-García I, Asensio-Vegas Á, Martínez-Ruiz R, Múñez-Rubio E, et al. Risk factors for Clostridium diffcile diarrhea in patients with infammatory bowel disease. Rev Esp Enferm Dig 2015;107:4-9.

22. Jen MH, Saxena S, Bottle A, Aylin P, Pollokà RCG. Increased health burden associated with Clostridium difficile diarrhoea in patients with inflammatory bowel disease. Aliment Pharmacol Ther 2011;33:1322-31. doi: 10.1111/j.1365-2036.2011.04661.x.

23. Fernandopulle ANR, Mayadunne PB, Navarathne NMM. The Prevalence of Clostridium difficile Infection in a Cohort of Sri Lankan Patients with Acute Severe Ul- cerative Colitis. Gastroenterol Hepatol Open Access 2014;1:00008. doi:10.15406/ghoa.2014.01.00008.

24. Sinh P, Barrett TA, Yun L. Clostridium difficile Infection and Inflammatory Bowel Disease: A Review. Gastroenterol Res Pract 2011;2011:136064. doi: 10.1155/2011/136064.

25. Trnka YM, LaMont JT. Association of Clostridium diffcile toxin with symptomatic relapse of chronic infammatory bowel disease. Gastroenterology 1981;80:693-6.

26. Bossuyt P, Verhaegen J, Van Assche G, Rutgeerts P, Vermeire S. Increasing incidence of Clostridium diffcile-associated diarrhea in infammatory bowel disease. J Crohn's Colitis 2009;3:4-7. doi:10.1016/j.crohns.2008.09.003.

27. Goodhand JR, Alazawi W, Rampton DS. Systematic review: Clostridium diffcile and infammatory bowel disease. Aliment Pharmacol Ther 2011;33:428-41. doi: 10.1111/j.1365-2036.2010.04548.x.

28. Wang Y, Atreja A, Wu X, Lashner BA, Brzezinski A, Shen B. Similar outcomes of IBD in patients with Clostridium diffcile infection detected by ELISA or PCR assay. Dig Dis Sci 2013;58:2308-13. doi:10.1007/s10620013-2641-x.

29. Schneeweiss S, Korzenik J, Solomon DH, Canning C, Lee J, Bressler B. Infliximab and other immunomodulating drugs in patients with infammatory bowel disease and the risk of serious bacterial infections. Aliment Pharmacol Ther 2009;30:253-64. doi:10.1111/j.13652036.2009.04037.x.

30. Das R, Feuerstadt P, Brandt LJ. Glucocorticoids are associated with increased risk of short-term mortality in hospitalized patients with clostridium diffcile associated disease. Am J Gastroenterol 2010;105:2040-9. doi:10.1038/ ajg.2010.142.

31. Berg AM, Kelly CP, Farraye FA. Clostridium diffcile infection in the infammatory bowel disease patient. Inflamm Bowel Dis 2013;19:194-204. doi:10.1002/ibd.22964.

32. Pascarella F, Martinelli M, Miele E, Del Pezzo M, Roscetto E, Staiano A. Impact of Clostridium diffcile infection on pediatric infammatory bowel disease. J Pediatr 2009;154:854-8. doi:10.1016/j.jpeds.2008.12.039.

33. Goodhand JR, Alazawi W, Rampton DS. Systematic review: Clostridium diffcile and infammatory bowel disease. Aliment Pharmacol Ther 2010;33:428-541. doi: 10.1111/j.1365-2036.2010.04548.x. 
34. Ananthakrishnan AN, Binion DG. Impact of Clostridium diffcile on infammatory bowel disease. Expert Rev Gastroenterol Hepatol 2010;4:589-600. doi:10.1586/egh.10.55.

35. Julie D'Aoust, Robert Battat, Talat Bessissow. Management of inflammatory bowel disease with Clostridium difficile infection. World J Gastroenterol 2017;23:49865003. doi:10.3748/wjg.v23.i27.4986.

36. Maharshak N, Barzilay I, Zinger H, Hod K, Dotan I. Clostridium difficile infection in hospitalized patients with inflammatory bowel disease Prevalence, risk factors, and prognosis. Medicine (Baltimore) 2018;97:e9772. doi: 10.1097/MD.0000000000009772.

37. Rao K, Higgins PD. Epidemiology, Diagnosis, and Management of Clostridium difficile Infection in Patients with Inflammatory Bowel Disease. Inflamm Bowel Dis 2016;22:1744-54. doi:10.1097/MIB.0000000000000793. 